\title{
Ischemic tolerance modulates TRAIL expression and its receptors and generates a neuroprotected phenotype
}

\author{
G Cantarella ${ }^{1,5}$, G Pignataro ${ }^{2,5}$, G Di Benedetto ${ }^{1}$, S Anzilotti ${ }^{3}$, A Vinciguerra ${ }^{2}$, 0 Cuomo ${ }^{2}$, GF Di Renzo ${ }^{2}$, C Parenti ${ }^{4}$, L Annunziato An $^{2,3}$ \\ and R Bernardini ${ }^{\star, 1}$
}

TNF-related apoptosis inducing ligand (TRAIL), a member of the TNF superfamily released by microglia, appears to be involved in the induction of apoptosis following focal brain ischemia. Indeed, brain ischemia is associated with progressive enlargement of damaged areas and prominent inflammation. As ischemic preconditioning reduces inflammatory response to brain ischemia and ameliorates brain damage, the purpose of the present study was to evaluate the role of TRAIL and its receptors in stroke and ischemic preconditioning and to propose, by modulating TRAIL pathway, a new therapeutic strategy in stroke. In order to achieve this aim a rat model of harmful focal ischemia, obtained by subjecting animals to $100 \mathrm{~min}$ of transient occlusion of middle cerebral artery followed by $24 \mathrm{~h}$ of reperfusion and a rat model of ischemic preconditioning in which the harmful ischemia was preceded by 30 mins of tMCAO, which represents the preconditioning protective stimulus, were used. Results show that the neuroprotection elicited by ischemic preconditioning occurs through both upregulation of TRAIL decoy receptors and downregulation of TRAIL itself and of its death receptors. As a counterproof, immunoneutralization of TRAIL in tMCAO animals resulted in significant restraint of tissue damage and in a marked functional recovery. Our data shed new light on the mechanisms that propagate ongoing neuronal damage after ischemia in the adult mammalian brain and provide new molecular targets for therapeutic intervention. Strategies aimed to repress the death-inducing ligands TRAIL, to antagonize the death receptors, or to activate the decoy receptors open new perspectives for the treatment of stroke.

Cell Death and Disease (2014) 5, e1331; doi:10.1038/cddis.2014.286; published online 17 July 2014

Stroke is a leading cause of death in industrialized countries ${ }^{1}$ and the most frequent cause of disability in adults. ${ }^{2}$ Although different mechanisms are involved in the pathogenesis of stroke, increasing evidence shows that ischemic injury and subsequent inflammation are responsible for damage progression, ${ }^{3}$ characterized by irreversible neuronal damage within minutes of the onset.

In the past 30 years, it has been demonstrated that the brain's resistance to ischemic injury can be transiently augmented by previous exposure to a non-injurious preconditioning (PC) stimulus. ${ }^{4}$ Evidence demonstrates that PC inhibits apoptosis in the penumbra region, thus preventing the spread of infarction. In addition, PC-induced neuroprotection appears related to a persistent activation of survival kinases in the penumbra. ${ }^{5} \mathrm{PC}$ seems recognized by sensor molecules, such as neurotransmitters, cytokines, and others, as a sign of an event potentially more severe to come. ${ }^{6}$ In particular, inflammatory cytokines, beside representing PC sensor molecules, have a relevant role in acute stroke. For instance, tumor necrosis factor- $\alpha$ (TNF- $\alpha)$ and IL-1 mediate the inflammatory/immune response related to progression of the ischemic lesion. ${ }^{7}$ In the brain, cytokines are expressed not only in systemic immunocytes but also in resident cells, including neurons and glia. ${ }^{8}$ In particular, microglia have a key role as immune-competent cells of the CNS. Recruitment of leukocytes from the blood stream and activation of microglia are thought to contribute to the extension of the infarct core into the surrounding penumbra. ${ }^{5}$ Substantial evidence demonstrates that ischemia-activated microglia releases several pro-inflammatory cytokines, as well as other potentially cytotoxic molecules, including NO, ROS, and eicosanoids. ${ }^{9}$ Such a large arsenal of cytotoxic molecules appear to be involved in the induction of neuronal death.

TNF-related apoptosis inducing ligand (TRAIL), a proapoptotic member of the TNF superfamily released by glia ${ }^{10,11}$ and injured neurons, ${ }^{12}$ appears to trigger apoptosis following focal brain ischemia. ${ }^{13}$ TRAIL binds five receptors, death receptor-4 (DR4), DR5, decoy receptor 1 (DcR1), DcR2, and osteoprogeterin. Although DR4 and DR5 receptors contain an intracellular death domain related to the apoptotic pathway, DcR1 and DcR2 serve as decoy receptors, ${ }^{14}$ eventually buffering death receptors' binding of TRAIL, thus preventing apoptosis. ${ }^{15,16}$

\footnotetext{
${ }^{1}$ Department of Clinical and Molecular Biomedicine, Section of Pharmacology and Biochemistry, School of Medicine, University of Catania, Viale Andrea Doria-6, Catania, Italy; ${ }^{2}$ Department of Neuroscience, Division of Pharmacology, School of Medicine, Federico II University of Naples, Via Pansini, 5, Naples, Italy; ${ }^{3}$ Fondazione IRCCS SDN, Via Gianturco, Naples, Italy and ${ }^{4}$ Department of Pharmaceutical Sciences, School of Pharmacy, University of Catania, Catania, Italy

${ }^{*}$ Corresponding author: R Bernardini, Department of Clinical and Molecular Biomedicine, Section of Pharmacology and Biochemistry, University of Catania Medical School, Viale Andrea Doria-6, Catania 95125, Italy. Tel: +39 0957384090; Fax: +39 0957384229; E-mail: bernardi@unict.it

${ }^{5}$ These authors contributed equally to this work.

Abbreviations: aCSF, artificial cerebral spinal fluid; DcR1, decoy receptor 1; DR4, death receptor-4; FasL, Fas ligand; JNK, Jun-N-terminal kinase; PC, preconditioning; tMCAO, transient middle cerebral artery occlusion; TNF- $\alpha$, tumor necrosis factor- $\alpha$; TNFR1, tumor necrosis factor receptor 1; TRAIL, TNF-related apoptosis inducing ligand

Received 04.3.14; revised 26.5.14; accepted 29.5.14; Edited by D Vucic
} 
Although recent work attempted to establish a relationship between TRAIL pathway and brain ischemia, ${ }^{17,18}$ only scant data are available on the role of TRAIL and its receptors in focal ischemia, ${ }^{19}$ and no data are known on the role of TRAIL in brain PC-induced neuroprotection.

In the present study, we evaluated the role of TRAIL and its receptors in stroke and ischemic PC and verified the hypothesis of a potential mode for therapeutic intervention in stroke, by administrating a specific anti-TRAIL antibody in rats subjected to transient middle cerebral artery occlusion (tMCAO).

\section{Results}

Intracerebroventricular (i.c.v.) injection of TRAIL abrogates beneficial effects of $P C$ in rats subjected to tMCAO. In order to determine the role of TRAIL in the neuroprotection exerted by ischemic PC, TRAIL was administered i.c.v. in rats. When TRAIL was injected both at $0.2 \mu \mathrm{g} / \mathrm{kg}$ and at $6 \mu \mathrm{g} / \mathrm{kg}$ immediately after tMCAO onset, it did not induce any significant change in total ischemic volume compared with vehicle-injected rats $(54 \pm 4.9$ and $47.8 \pm 1.9 \%$ versus $58.6 \pm 3.5 \%$, respectively). Conversely, when TRAIL was administered i.c.v. at $6 \mu \mathrm{g} / \mathrm{kg}$ in rats undergone the same surgical procedure preceded by $\mathrm{PC}$, it was able to induce a significant increase in the ischemic volume compared with the vehicle-injected rats $(54.4 \pm 9.1$ versus $22.2 \pm 2.7 \%$ ). Ischemic volume did not change when preconditioned rats were i.c.v. treated with vehicle or with TRAIL $0.2 \mu \mathrm{g} / \mathrm{kg}$ (22.2 \pm 2.8 versus $24 \pm 4.8 \%$; Figure 1a). These data were mirrored by data on neurological scores. Indeed, a worsening in neurological deficits was observed in preconditioned animals treated with TRAIL $6 \mu \mathrm{g} / \mathrm{kg}$ compared with vehicle-treated animals (Figure 1b).

Expression of TRAIL and its death and decoy receptors is modulated, along with that of inflammatory molecules, by tMCAO-induced brain ischemia and by ischemic PC. Expression levels of TRAIL and both classes
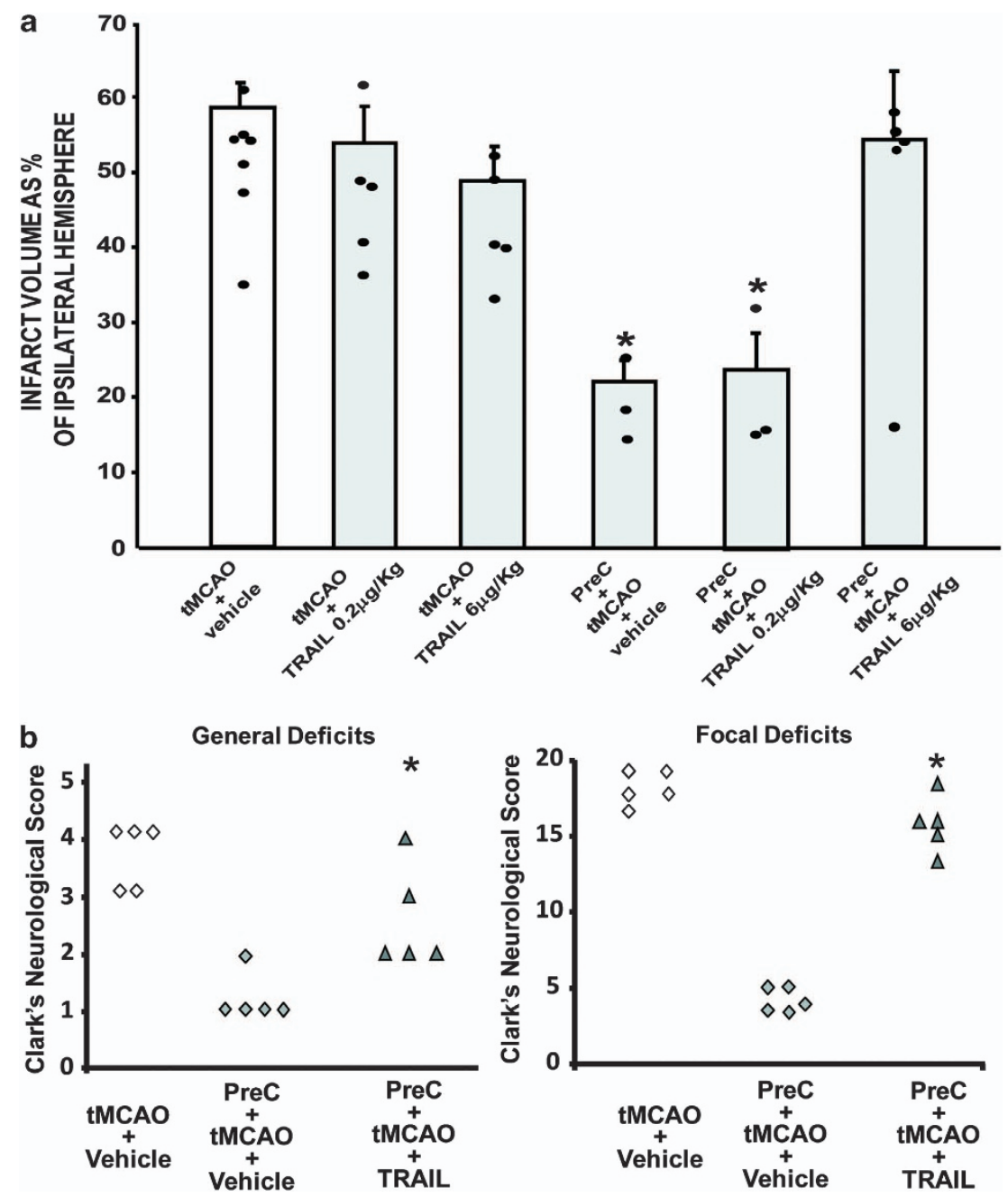

Figure 1 Effect of TRAIL administration on neuroprotection elicited by ischemic preconditioning. (a) $6 \mu \mathrm{g} / \mathrm{kg}$ TRAIL i.c.v. administered determines the loss of the neuroprotection elicited by ischemic PC. Infarct volume in rats subjected to tMCAO + Vehicle, tMCAO + $0.2 \mu \mathrm{g} / \mathrm{kg}$ TRAIL, tMCAO + $6 \mu \mathrm{g} / \mathrm{kg}$ TRAIL, PC + tMCAO + Vehicle, $\mathrm{PC}+\mathrm{tMCAO}+0.2 \mu \mathrm{g} / \mathrm{kg}$ TRAlL, and PC + tMCAO $+6 \mu \mathrm{g} / \mathrm{kg}$ TRAlL. Rats were euthanized $24 \mathrm{~h}$ after tMCAO. ${ }^{*} P<0.05$ versus all experimental groups. Each column represents the mean \pm S.E.M. $(n=3-7)$ of the percentage of the infarct volume compared with the ipsilateral hemisphere. (b) A total of $6 \mu \mathrm{g} / \mathrm{kg}$ TRAlL i.c.v. administered worsens general and focal deficits in rats subjected to $\mathrm{PC}+\mathrm{tMCAO}$. ${ }^{*} \mathrm{P}<0.05$ versus $\mathrm{PC}+$ vehicle-treated animals 
of its receptors, death DR4 and DR5, and decoy DcR1 and DcR2 were studied by western blotting analysis in animals subjected to PC, tMCAO, or PC followed, $72 \mathrm{~h}$ later, by tMCAO. All animals were then allowed to 24-h reperfusion.

Expression of TRAIL increased significantly in rats subjected to tMCAO after $24 \mathrm{~h}$ of reperfusion. This increased expression of TRAIL was dramatically reduced in the temporoparietal brain cortices of animals exposed to either $\mathrm{PC}$ alone or PC followed by tMCAO.

The increased expression of both DR4 and DR5 death receptors in the $\mathrm{MCAO}$ experimental group closely paralleled that of TRAIL. In particular, DR4 and DR5 expression, after
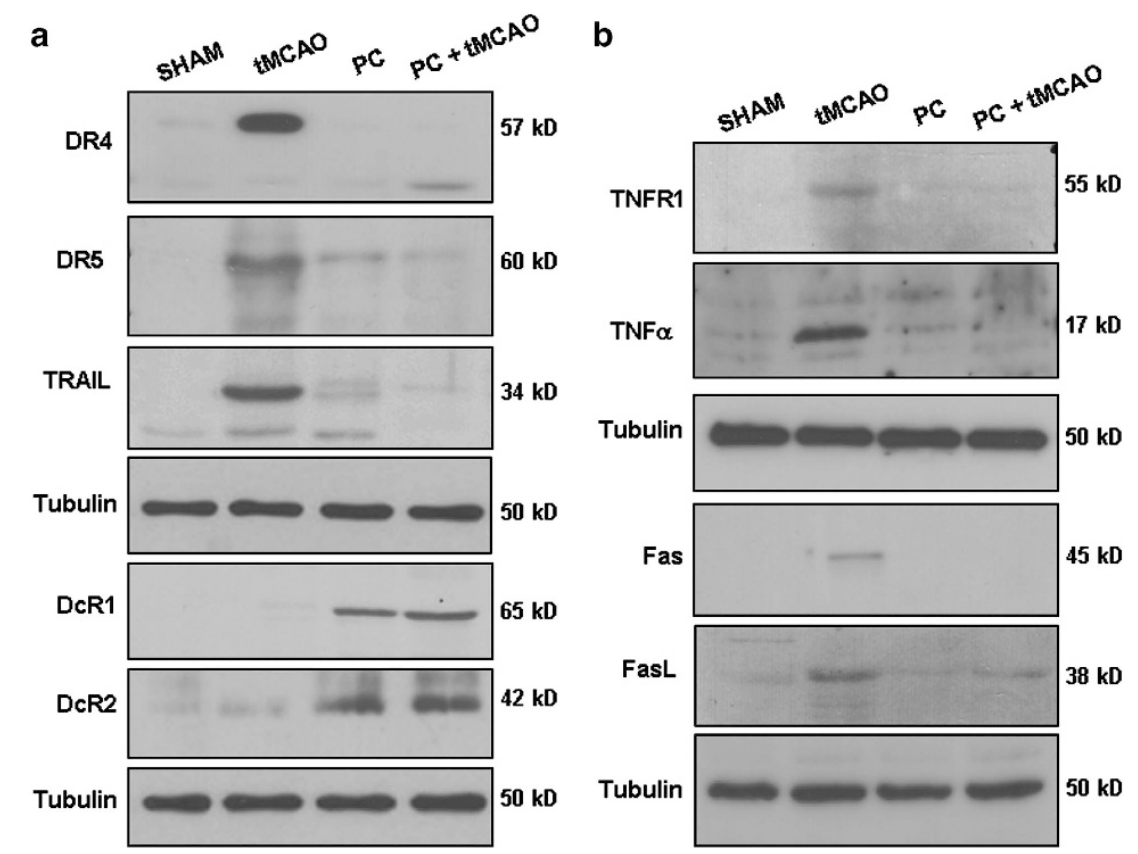

Figure 2 Effect of tMCAO/PC followed by $24 \mathrm{~h}$ of reperfusion on either TRAIL and its receptor's protein expression, as well as on TNF- $\alpha$, FasL, and their respective receptors. (a) Representative blots of DR4, DR5, TRAIL, DcR1, and DcR2 protein expression in sham-operated animals (SHAM) or after 100 min tMCAO (tMCAO), 30 min tMCAO (PC), and $30 \mathrm{~min} P C$, followed, $72 \mathrm{~h}$ later, by $100 \mathrm{~min}$ tMCAO (PC + tMCAO) in the ipsilateral temporoparietal cortex after $24 \mathrm{~h}$ of reperfusion. Tubulin blots: $\beta$-tubulin (respective controls). (b) Representative blots of TNFR1, TNF- $\alpha$, Fas, and FasL protein expression in sham-operated animals (SHAM) and after 100 min tMCAO (tMCAO), $30 \mathrm{~min}$ tMCAO (PC), and $30 \mathrm{~min}$ PC, followed, $72 \mathrm{~h}$ later, by $100 \mathrm{~min}$ tMCAO (PC + tMCAO) in the ipsilateral temporoparietal cortex after $24 \mathrm{~h}$ of reperfusion. Tubulin blots: $\beta$-tubulin (respective controls)

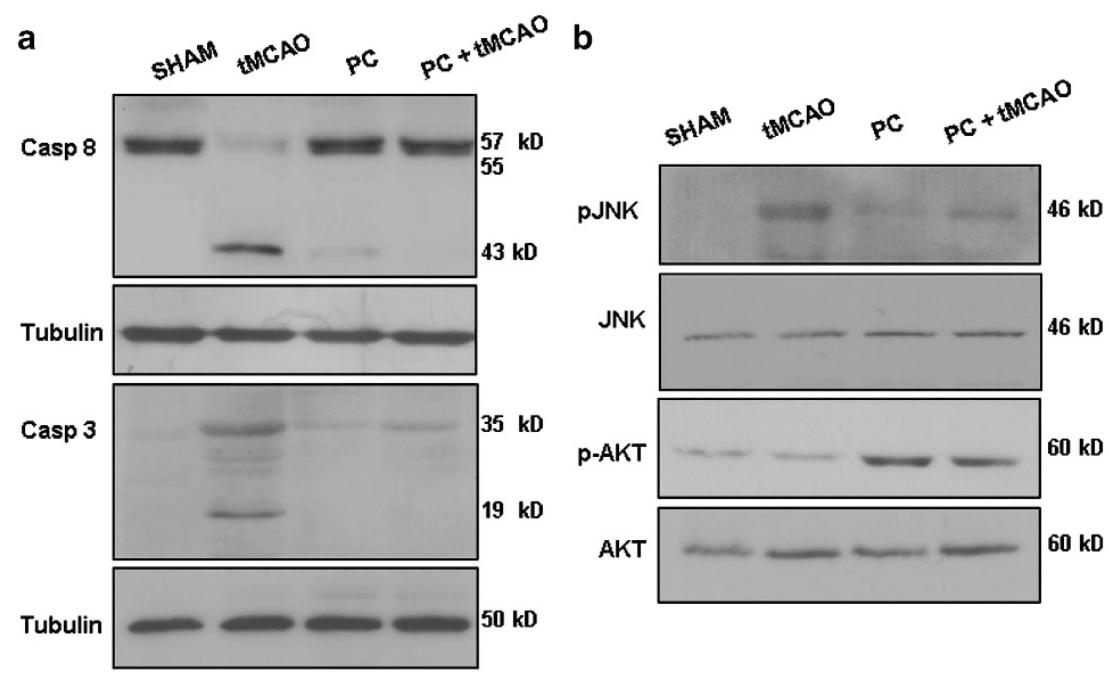

Figure 3 Effect of tMCAO/PC followed by $24 \mathrm{~h}$ of reperfusion on either caspases-8 and -3 , TRAIL pathway-related kinase JNK, and the cell survival-related kinase Akt. (a) Representative blots of caspase- 8 and caspase- 3 protein expression in sham-operated animals (SHAM) and after 100 min tMCAO (tMCAO), 30 min tMCAO (PC), and $30 \mathrm{~min}$ preconditioning, followed, $72 \mathrm{~h}$ later, by $100 \mathrm{~min}$ tMCAO $(\mathrm{PC}+\mathrm{tMCAO})$ in the ipsilateral temporoparietal cortex after $24 \mathrm{~h}$ of reperfusion. Tubulin blots: $\beta$-tubulin (controls). (b) Representative blot of phospho-JNK and phospho-AKT protein expression in sham-operated animals (SHAM) or after 100 min tMCAO (tMCAO), 30 min tMCAO (PC), and $30 \mathrm{~min}$ PC, followed, $72 \mathrm{~h}$ later, by $100 \mathrm{~min}$ IMCAO (PC + tMCAO) in the ipsilateral temporoparietal cortex after $24 \mathrm{~h}$ of reperfusion. Unphosphorylated JNK and AkT are controls 
PC, was comparable to normal controls and dramatically resulted in decrease after PC followed by tMCAO.

Conversely, the expression of both TRAIL-neutralizing receptors DcR1 and DcR2 was substantially reduced in animals undergone $\mathrm{TMCAO}$, whereas a significant increase occurred in animals undergone PC only. The expression of both DcR1 and 2 was even more intense in animals receiving both PC and tMCAO (Figure 2a).

As TRAIL is known to significantly increase the expression of related inflammatory molecules, ${ }^{20}$ the expression of TNF- $\alpha$, Fas ligand (FasL) and their respective death receptors tumor necrosis factor receptor 1 (TNFR1) and Fas was also measured.

Although tMCAO significantly increased the expression of all the proteins studied, on the other hand, expression of TNF- $\alpha$, FasL, TNFR1 and Fas was decreased by PC and, more substantially, when applying PC before tMCAO (Figure 2b).

Moreover, as caspase-8 and caspase- 3 pathways are both activated by TRAIL and the resulting increased cell death rate involves activation of related kinase Jun-N-terminal kinase (JNK), in order to verify whether the molecular mechanisms underlying the effects of TRAIL were actually set into motion, cleavage of downstream caspase- 8 and caspase- 3 was first evaluated in the same lysates, along with phosphorylation of JNK.

As a consequence of $\mathrm{MCAO}$, both caspase- 8 and caspase- 3 were substantially cleaved (i.e., activated), whereas caspase cleavage was significantly reduced in animals undergone PC, and almost totally abrogated in rats undergone precondition procedure before tMCAO (Figure 3a).

In parallel, phosphorylation of JNK, which was significantly increased in rats undergone $\mathrm{TMCAO}$, was comparable to basal levels either in rats with $\mathrm{PC}$ alone or in rats undergone PC before tMCAO (Figure $3 \mathrm{~b}$ ). By contrast, to correlate the increased expression of the TRAIL DcR1 and DcR2 decoy receptors to the survival kinases AKT, we evaluated the phosphorylation of the latter. Accordingly with the expression level of the two decoy receptors, phospho-AKT was substantially reduced in the tMCAO group, whereas $\mathrm{PC}$ and $\mathrm{PC}+$ tMCAO produced its robust increase (Figure $3 b$ ).

Confocal immunofluorescence imaging of TRAIL expression at different time intervals after tMCAO, PC and PC + tMCAO in the ipsilateral peri-ischemic region. TRAIL expression has been evaluated at different time intervals by immunofluorescence in tissue slices from ipsilesional temporoparietal cortex of ischemic rats subjected to $100 \mathrm{~min} \mathrm{tMCAO}$, preconditioned rats $(30 \mathrm{~min}+\mathrm{tMCAO})$ and ischemic preconditioned rats $(30 \mathrm{~min} \mathrm{tMCAO}$, followed, $72 \mathrm{~h}$ later, by $100 \mathrm{~min}$ tMCAO).

Double fluorescence immunostaining of both TRAIL and the neuronal marker NeuN has revealed that, in ischemic rats, robust TRAIL immunoreactivity is localized mainly in the cytosol and in the nuclei of neurons. Differently, when rats were subjected to PC alone or to PC followed by tMCAO, TRAIL immunoreactivity was expressed only at the cytoplasmatic level.

With regard to TRAIL expression, immunofluorescent data confirmed those obtained with western blotting, showing an increase in TRAIL expression when rats were subjected to harmful ischemia (100 min tMCAO), and a substantial
A
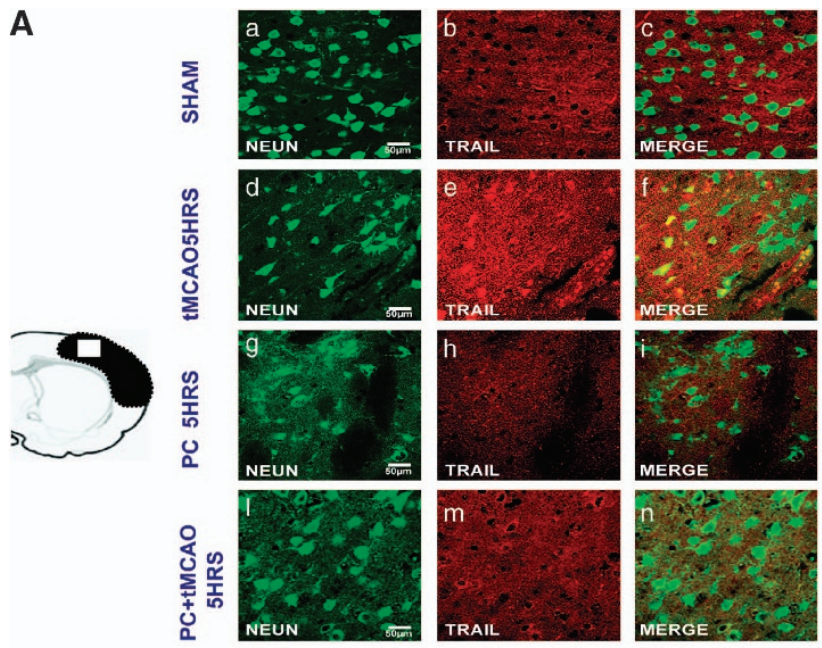

B
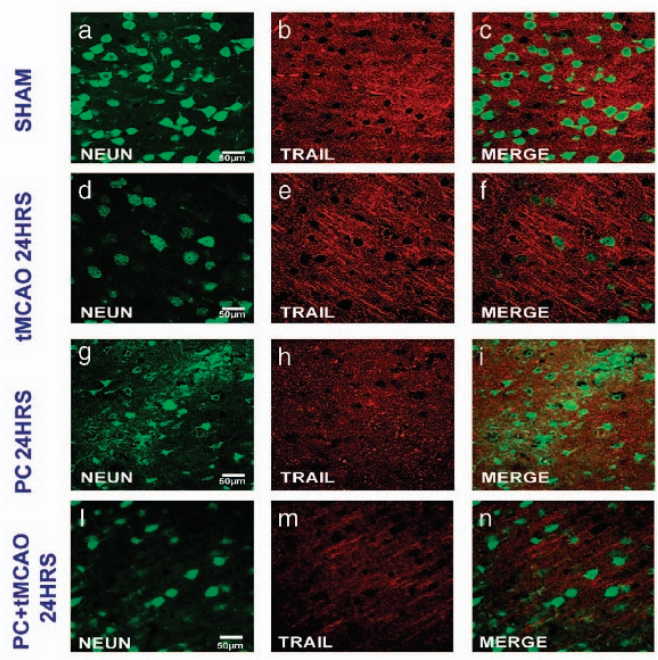

C
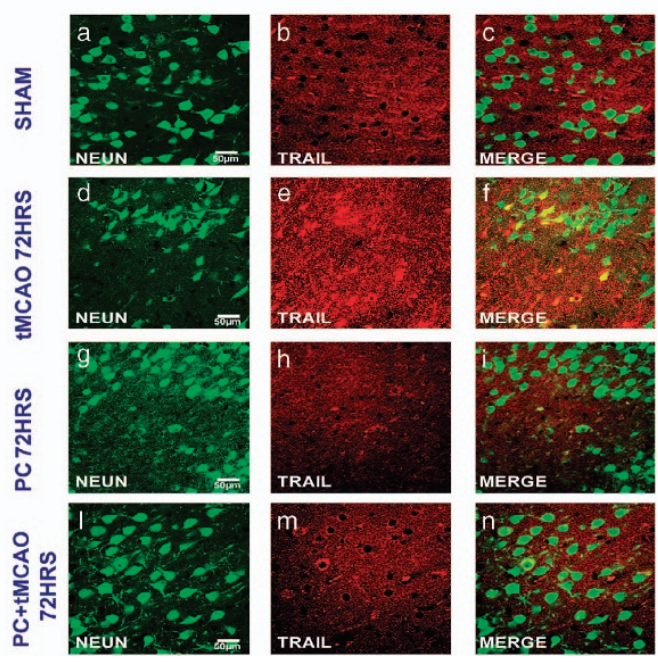

Figure 4 Effect of 100 min of transient brain ischemia (tMCAO), ischemic PC, and $\mathrm{PC}$ followed $72 \mathrm{~h}$ later by tMCAO (PC + tMCAO) on TRAlL expression. Confocal microscopic images displaying NeuN (a-l) (green), TRAIL (b-m) (red), and Merge (c-n) (yellow) in the brain peri-ischemic region of rats after $5 \mathrm{~h}(\mathrm{~A}), 24 \mathrm{~h}(\mathrm{~B})$, and $72 \mathrm{~h}(\mathbf{C})$ of reperfusion. A representative brain slice cartoon indicating the area of interest is on the left top of the figure. Scale bars in a-i: $50 \mu \mathrm{m}$ 
A
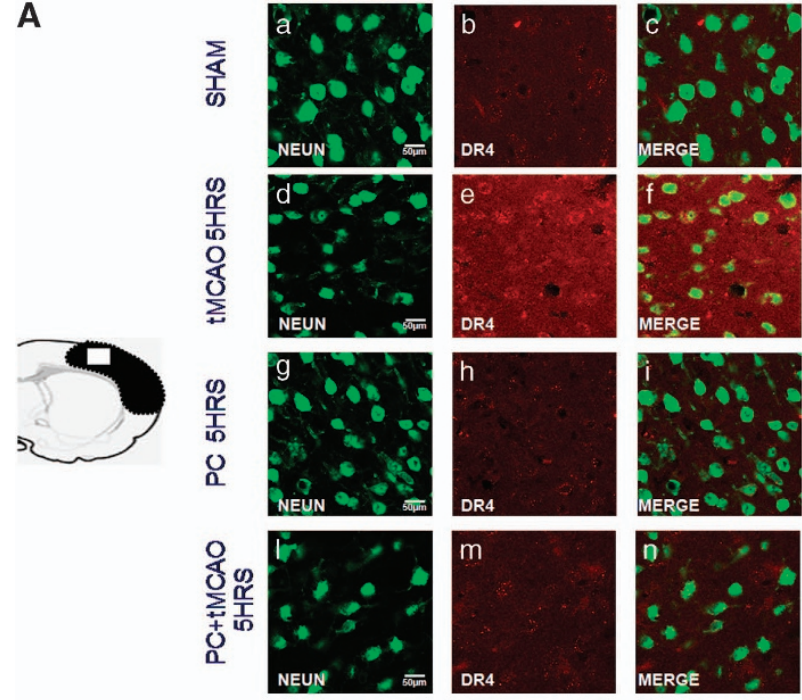

B
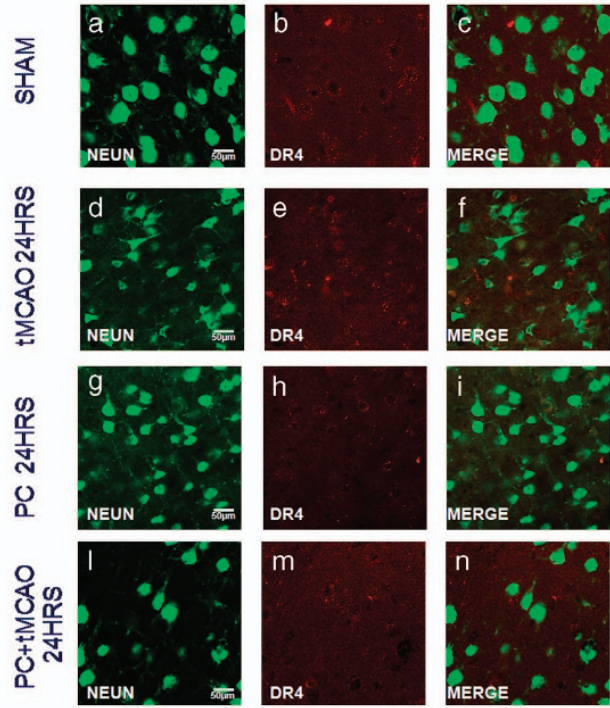

C
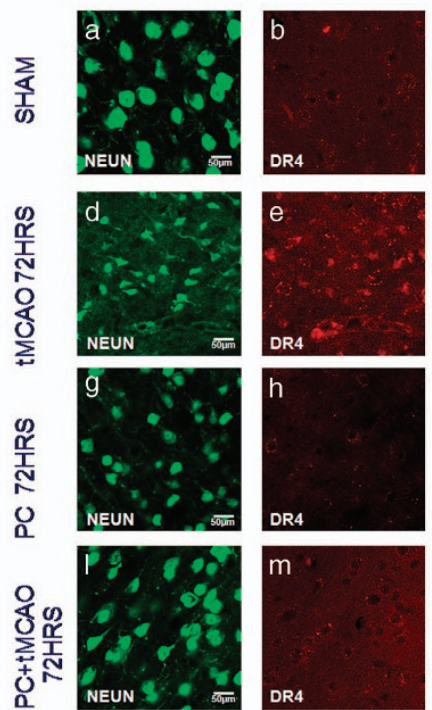
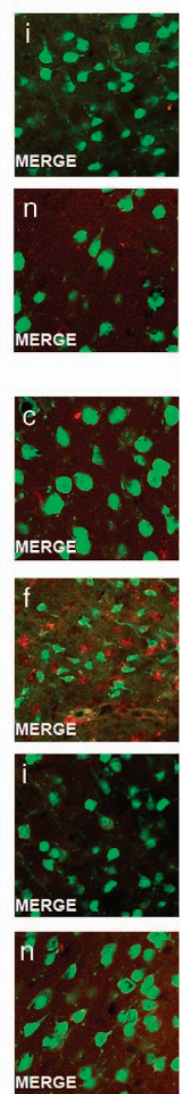

reduction of TRAIL expression when the animals were exposed to PC or to PC followed by tMCAO. These data were confirmed at all the time intervals considered, 5, 24, and $72 \mathrm{~h}$ of reperfusion (Figures $4 \mathrm{~A}-\mathrm{C}$ ).

Ischemic PC induces decreased expression of TRAIL death receptor DR4 and DR5 in parallel to overexpression of its decoy receptors, DcR1 and DcR2. In order to establish whether the loss of neuroprotection observed after TRAIL overexpression could be related to changes in the expression of DR4-DR5 and DcR1-DcR2, the expression of these proteins was evaluated by means of confocal microscopy analysis on coronal brain tissue slices of rats subjected to tMCAO, ischemic PC, or ischemic PC followed by $100 \mathrm{~min} \mathrm{IMCAO}$ at 5,24 , and $72 \mathrm{~h}$ of reperfusion.

Interestingly, an inverse relationship between TRAIL death receptor expression and decoy receptor was observed.

In fact, both DR4 and DR5 protein expression increased during $\mathrm{TMCAO}$ and decreased after PC and after PC followed by $\mathrm{IMCAO}$, thus indicating that this protein is having a detrimental role during the ischemic process (Figures 5 and $6 \mathrm{~A}-\mathrm{C})$.

On the other hand, the expression of DcR1 and DcR2 was significantly reduced after harmful ischemia, whereas its expression increased after PC + tMCAO at all the considered reperfusion time intervals, suggesting that a possible buffering role of DcR1-DcR2 is set into motion to counteract TRAILinduced neuronal death (Figures 7 and $8 \mathrm{~A}-\mathrm{C}$ ).

Intracerebroventricular injection of an anti-TRAIL monoclonal antibody induces neuroprotection in rats subjected to IMCAO. To corroborate the hypothesis of the detrimental role of TRAIL in brain ischemia, a TRAILneutralizing antibody (CD253, anti-TRAIL) was injected i.c.v. in rats subjected to $100 \mathrm{~min}$ tMCAO, followed by $24 \mathrm{~h}$ reperfusion. Each rat received a total volume of $20 \mu \mathrm{l}$, four times. Although anti-TRAIL at a low dose was not able to exert any significant effect $(51.5 \pm 4.1$ versus $58.6 \pm 3.5 \%)$, when anti-TRAIL was administered at $200 \mu \mathrm{g} / \mathrm{kg}$, it determined a significant reduction of the ischemic volume in comparison with ischemic animals treated with the antiidiotype $(30.1 \pm 5.8$ versus $58.6 \pm 3.5 \%)$. No effects were observed when scrambled anti-TRAIL was administered ( $55.4 \pm 3.8$ versus $58.6 \pm 3.5 \%$; Figure $9 a$ ).

To assess whether the decrease in the infarct volume observed after i.c.v. administration of anti-TRAIL $200 \mu \mathrm{g} / \mathrm{kg}$ in ischemic rats was accompanied by an amelioration in neurological deficits, animals were scored for general and focal neurological deficits immediately before they were killed. Results demonstrated that anti-TRAIL, injected i.c.v., besides decreasing the brain infarct volume, was also able to decrease focal and general neurological scores when evaluated at $24 \mathrm{~h}$ (Figure 9b).

Figure 5 Effect of 100 min of transient brain ischemia (tMCAO), ischemic PC, and $\mathrm{PC}$ followed $72 \mathrm{~h}$ later by $\mathrm{TMCAO}(\mathrm{PC}+\mathrm{tMCAO}$ ) on DR4 expression. Confocal microscopic images displaying NeuN (a-l) (green), DR4 (b-m) (red), and Merge (c-n) (yellow) in the brain peri-ischemic region of rats after $5 \mathrm{~h}(\mathrm{~A}), 24 \mathrm{~h}(\mathrm{~B})$, and $72 \mathrm{~h}$ (C) of reperfusion. A representative brain slice cartoon indicating the area of interest is on the left top of the figure. Scale bars in a-i: $50 \mu \mathrm{m}$ 
A
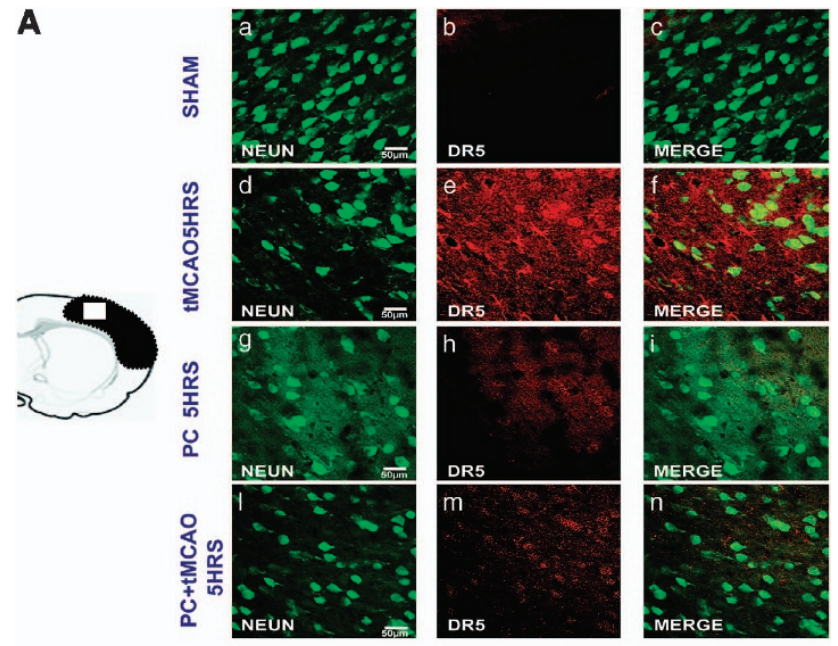

B
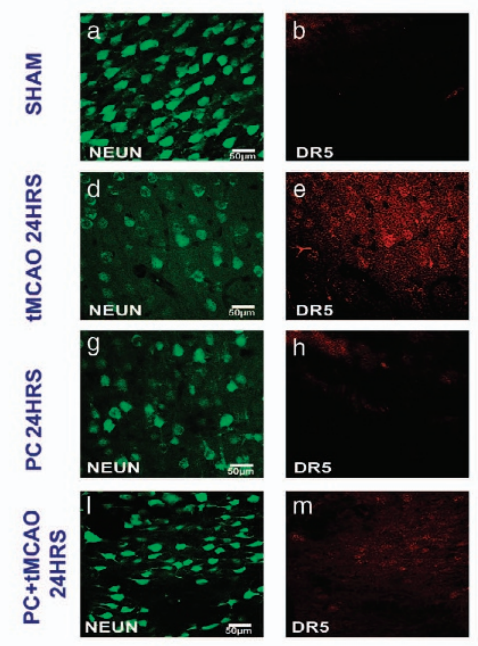

C
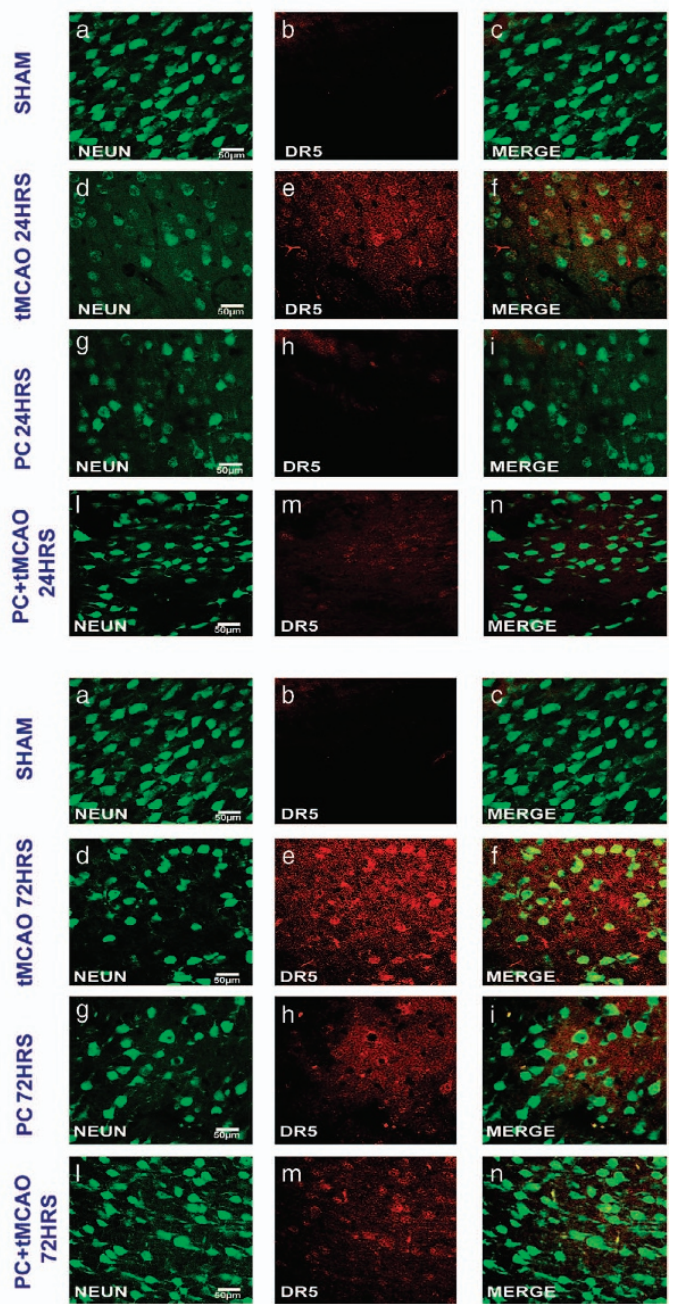

Figure 6 Effect of 100 min of transient brain ischemia (tMCAO), ischemic PC, and $\mathrm{PC}$ followed $72 \mathrm{~h}$ later by tMCAO (PC + tMCAO) on DR5 expression. Confocal microscopic images displaying NeuN (a-l) (green), DR5 (b-m) (red), and Merge $(\mathrm{C}-n)$ (yellow) in the brain peri-ischemic region of rats after $5 \mathrm{~h}(\mathbf{A}), 24 \mathrm{~h}(\mathrm{~B})$, and $72 \mathrm{~h}$ (C) of reperfusion. A representative brain slice cartoon indicating the area of interest is on the left top of the figure. Scale bars in a-i: $50 \mu \mathrm{m}$

\section{Discussion}

This study provides evidence that the neuroprotection elicited by ischemic PC occurs either through upregulation of the TRAIL decoy receptor DcR2 and through downregulation of TRAIL and its death receptor DR5. In addition, here we propose an experimental strategy for inducing stroke neuroprotection by modulating TRAIL activity by using in vivo the selective monoclonal antibody anti-TRAIL.

Although the biological importance of TRAIL is not completely understood, it appears that this protein may have a critical role in cellular response to environmental stress. ${ }^{11,21-23}$ As such, TRAIL signaling also promotes an array of biological responses associated with cellular growth and survival. ${ }^{24}$ In line with these findings, we report novel evidence here that TRAIL is upregulated in the ischemic brains of animals subjected to focal ischemia, whereas it appears dramatically downregulated in the brains of animals subjected to a sub-lethal ischemia, PC, or an harmful ischemia preceded by PC. Given that TRAIL represents the ligand for two death receptors and for two decoy receptors, we also evaluated the expression profile of these receptors after stroke, and we observed that the increase in TRAIL would undoubtedly complement the increase of its death receptors DR4 and DR5, while its downregulation parallels the increased expression of its decoy receptors DcR1 and DcR2, resulting in a substantial increase in TRAIL signaling following stroke and a substantial decrease in TRAIL pathway after ischemic PC. Significant increase in the expression of the DcR1/DcR2 receptors, which is known to bind TRAIL not bringing about any signal transduction, ${ }^{15}$ appears to be of special interest in the ischemic context, as it represents a modality of neutralizing a part of TRAIL and its effects, which include sustained cell death rates. ${ }^{25}$ Such hypothesis is supported by the parallel increase of the cell survival-related kinase $A k T,{ }^{5}$ indicating that $\mathrm{PC}$ prevents detrimental effects of TRAIL and sets into motion the cell survival machinery to rescue neurons to death.

At any rate, detrimental effects of TRAIL appeared mediated through activation of caspase- 8 and -3 , as well as phosphorylation of the stress kinase JNK, both key elements involved in transduction of the TRAIL-dependent cell death signaling, ${ }^{26,27}$ thus corroborating the hypothesis that TRAIL could represent a substantial contributor to poststroke neurodegeneration processes.

Consistent with the findings that TRAIL overexpression is deleterious, whereas TRAIL reduction is neuroprotective following stroke, ${ }^{17}$ our data provide evidence that TRAIL downregulation is, indeed, crucial to stroke recovery. This represents an important finding, as, so far, few studies have investigated the role of TRAIL in cell death induced by ischemia, ${ }^{17-19,28}$ and no one investigated about the possible involvement of TRAIL in the neuroprotective phenomenon known as ischemic PC.

In fact, the overexpression of TRAIL and its death receptors after hypoxia-ischemia has been underlined in some seminal papers. ${ }^{18,28}$ Indeed, TRAIL and DR5 are upregulated in the immature rat brain after perinatal hypoxia-ischemia ${ }^{18}$ as well as after transient global ischemia. ${ }^{17}$ In addition, it has been shown that blocking 


\section{A}
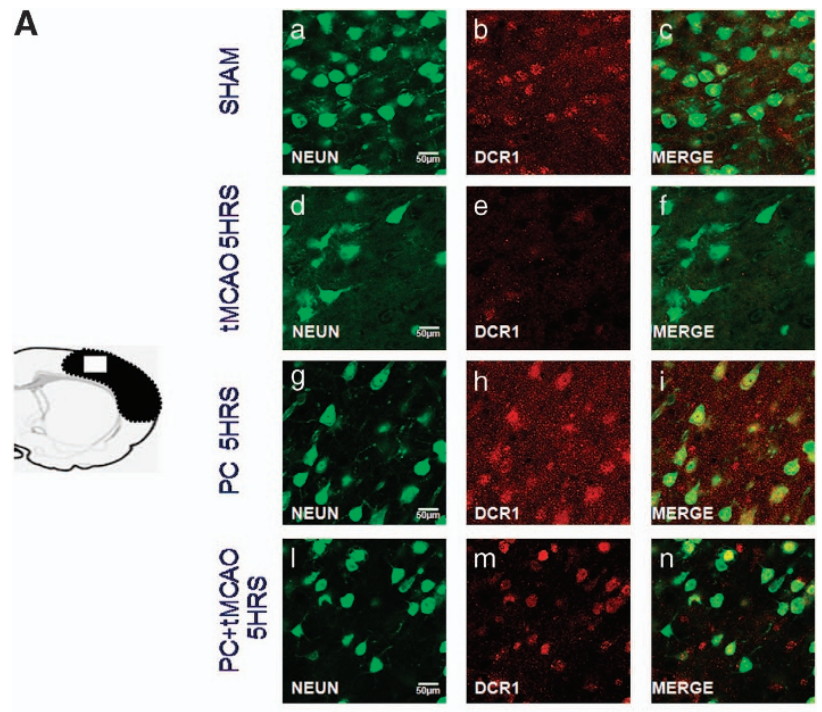

B
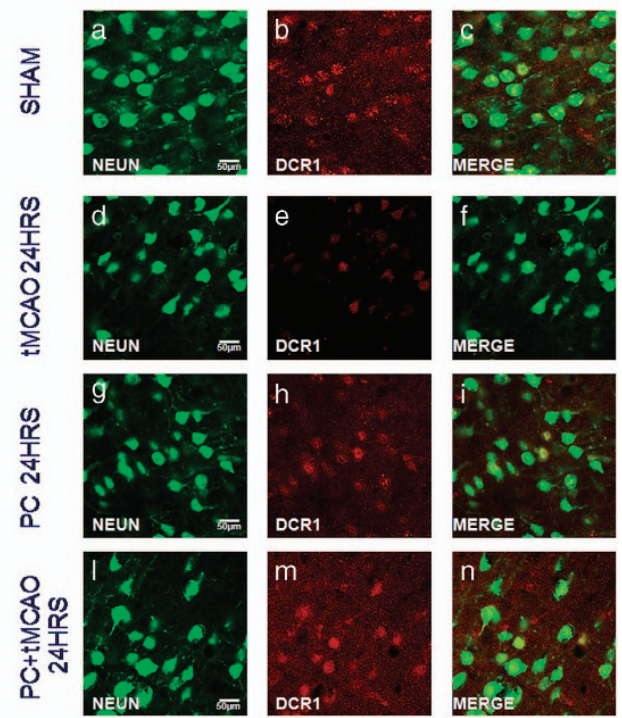

\section{C}
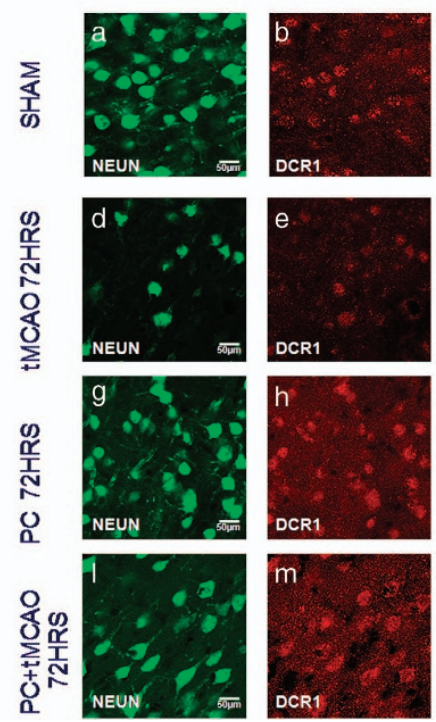

TRAIL by soluble DR5 mitigate selective neuronal death after transient global ischemia-reperfusion in mice. ${ }^{17}$

In addition, increased TRAIL expression was paralleled by the increased levels of proinflammatory molecules, such as TNF- $\alpha$ and its death receptor TNFR1 or FasL and its receptor Fas. It is known that one of the biological properties displayed by cytokines, regardless of their biological role, is redundancy, ${ }^{29}$ and we have shown that the increase of tissue TRAIL expression in a murine model of spinal cord injury is paralleled by an increase of both tissue TNF- $\alpha$ and FasL expression. ${ }^{20}$ Thus it is plausible that such potent effects of TRAIL in inducing poststroke neuronal death is also related to redundancy with two cytokines, TNF- $\alpha$ and FasL, possessing similar properties, ${ }^{30}$ therefore potentiating TRAIL-induced neuronal death, via binding to their own death receptors.

Thus we went on and proposed a feasible therapeutic strategy for stroke, based on the use of a monoclonal antibody against TRAIL as a potential compound to be used in stroke intervention. In particular, we mimicked the protective effect mediated by ischemic PC by administering anti-TRAIL to ischemic rats and proposed new insights into the putative mechanisms by which ischemic PC exerts its protective effect, with restored functional parameters.

Concerning a possible mechanism by which PC influences the expression of TRAIL and its receptor, it is possible to hypothesize that the two transcriptional factors NFKB and HIF, involved in $\mathrm{PC}$ neuroprotection, ${ }^{31,32}$ may have a fundamental role. Interestingly, recent findings demonstrated that both these factors are tightly linked to TRAIL and its receptors. Indeed, the C-terminal element of DcR2 has signaling capacity similar to that of DR4 and DR5 with respect to $\mathrm{NF} \kappa \mathrm{B}$ activation ${ }^{33}$ but is unable to induce apoptosis. Thus increased expression of TRAIL decoy receptors by IPC may activate a secondary complex-linked survival kinase pathway. Studies implicating $\mathrm{NF} \kappa \mathrm{B}$ in TRAIL-induced apoptosis are few in number and conflicting. $\mathrm{NF} \kappa \mathrm{B}$ expression is shown to be involved in protection against TRAIL, ${ }^{34}$ but a functional NFKB binding site is located in the promoter region of DR4 ${ }^{35} \mathrm{NF} \kappa \mathrm{B}$ has been reported to enhance TRAIL-induced apoptosis through intronic regulation of DR5. ${ }^{36}$ In addition, DcR2 expression can be induced by the other above mentioned transcription factor $\mathrm{HIF}^{37}$ that is strongly upregulated by ischemic $P C .^{32}$

In conclusion, we detected upregulation of TRAIL and its death receptors, DR4 and DR5, as well as a reduction in the expression of the decoy receptors, DcR1 and DcR2, in the postischemic brain, whereas an opposite expression behavior was observed for the same proteins in the protected preconditioned brain, thus demonstrating, in vivo, their potency to mediate cell death or protection.

Our data shed new light on the mechanisms that propagate ongoing neuronal damage after ischemia in the adult mammalian brain and provide new molecular targets for therapeutic intervention. Strategies aimed to repress either

Figure 7 Effect of 100 min of transient brain ischemia (tMCAO), ischemic PC, and $P C$ followed $72 \mathrm{~h}$ later by tMCAO (PC + tMCAO) on DcR1 expression. Confocal microscopic images displaying NeuN (A-L) (green), DcR1 (b-m) (red), and Merge $(c-n)$ (yellow) in the brain peri-ischemic region of rats after $5 \mathrm{~h}(\mathbf{A}), 24 \mathrm{~h}$ (B), and $72 \mathrm{~h}(\mathrm{C})$ of reperfusion. A representative brain slice cartoon indicating the area of interest is on the left top of the figure. Scale bars in a-i: $50 \mu \mathrm{m}$ 
A
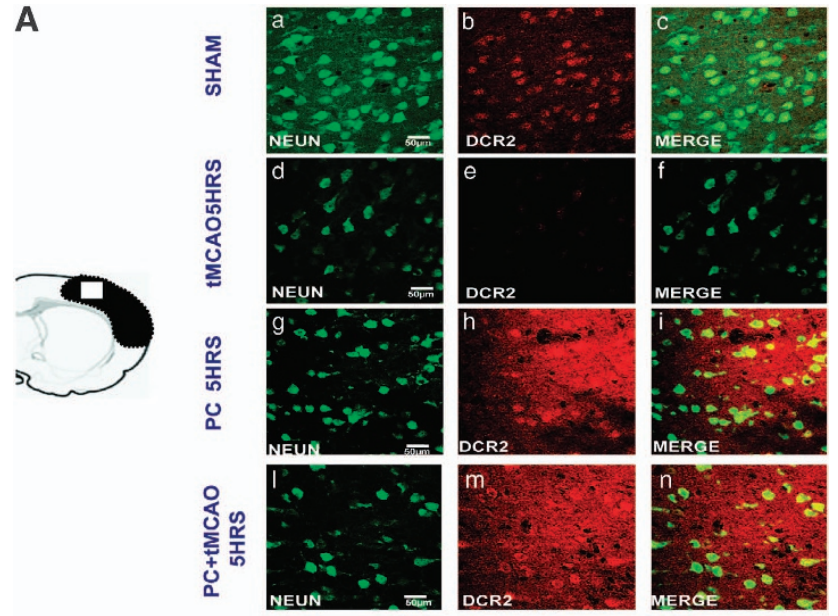

B
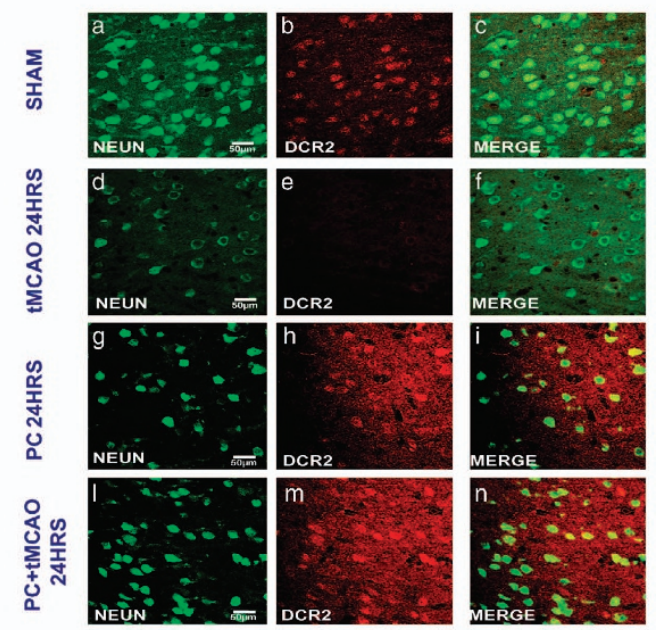

C
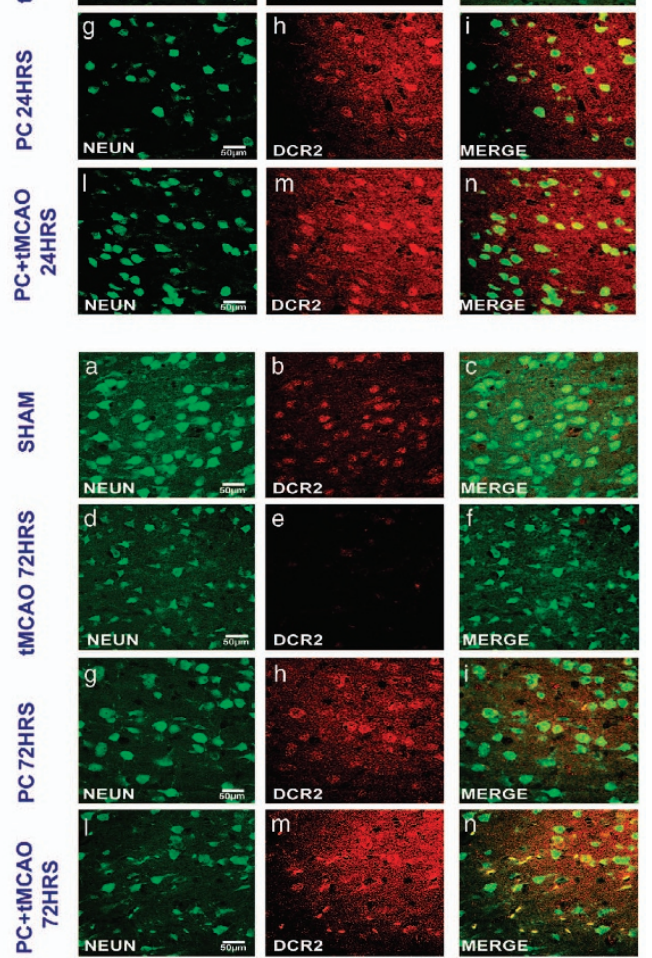

Figure 8 Effect of 100 min of transient brain ischemia (tMCAO), ischemic PC, and $\mathrm{PC}$ followed $72 \mathrm{~h}$ later by $\mathrm{MCAO}(\mathrm{PC}+\mathrm{tMCAO})$ on DcR2 expression. Confocal microscopic images displaying NeuN (a-l) (green), DcR2 (b-m) (red), and Merge (c-n) (yellow) in the brain peri-ischemic region of rats after $5 \mathrm{~h}(\mathbf{A}), 24 \mathrm{~h}(\mathbf{B})$, and $72 \mathrm{~h}(\mathrm{C})$ of reperfusion. A representative brain slice cartoon indicating the area of interest is on the left top of the figure. Scale bars in a-i: $50 \mu \mathrm{m}$

the death-inducing ligands TRAIL, to antagonize death receptor, DR5, or to activate the decoy receptor, DcR2, open new perspectives for the treatment of stroke.
Materials and methods

Animals. One hundred and fifteen male Sprague Dawley rats (250-270 g; Charles River, Lecco, Italy) housed five per cage under diurnal lighting conditions $(12 \mathrm{~h}$ dark-light cycle) were used in the present study. Experiments were performed in full accordance with the international guidelines for animal research and humane care. The experimental protocol was approved by the Animal Care Committee of the 'Federico II' University of Naples, Italy.

Experimental groups and surgical procedures. Transient focal ischemia was induced as previously described ${ }^{38}$ by suture occlusion of the MCA in male rats anesthetized using $1.5 \%$ sevoflurane, $70 \% \mathrm{~N}_{2} \mathrm{O}$, and $28.5 \% \mathrm{O}_{2}$. Achievement of ischemia was confirmed by monitoring regional cerebral blood flow through laser Doppler (PF5001; Perimed, Jarfalla, Sweden). Animals not showing a cerebral blood flow reduction of at least $70 \%$ were excluded from the study. Before treatment, rats were randomly divided into three main experimental groups: (1) preconditioned, (2) ischemic, and (3) preconditioned ischemic rats (undergone $\mathrm{PC}+\mathrm{tMCAO}$ ). The sham-operated animals underwent the same experimental conditions except that the occluding filament was not introduced in the vessel lumen; in the ischemic group, the MCA was occluded for $100 \mathrm{~min}$; in the preconditioned ischemic group, rats were subjected to $30 \mathrm{~min}$ of $\mathrm{tMCAO} 72 \mathrm{~h}$ before $100 \mathrm{~min}$ of tMCAO. All animals were killed by decapitation $24 \mathrm{~h}$ after $100 \mathrm{~min}$ of $\mathrm{MCAO}$ to quantify the infarct volume. Rectal temperature was maintained at $37 \pm 0.5^{\circ} \mathrm{C}$. Blood gas analysis was carried out in all animals, and no differences in $\mathrm{pH}, \mathrm{pCO}_{2}$ and $\mathrm{PO}_{2}$ was detected among all the experimental groups.

Intracerebroventricular (i.c.v.) administration. In rats positioned on a stereotaxic frame, a 23-g stainless steel guide cannula was implanted into the right lateral ventricle using the stereotaxic coordinates from the bregma: $0.4 \mathrm{~mm}$ caudal, $2 \mathrm{~mm}$ lateral and $2 \mathrm{~mm}$ below the dura. ${ }^{39}$ TRAIL at doses ranging from 0.2 to $6 \mu \mathrm{g} / \mathrm{kg}$ was administered in a final volume of $5 \mu$, either immediately after tMCAO induction or after PC + ischemia. Conversely, anti-TRAIL (20 and $200 \mu \mathrm{g} / \mathrm{kg}$, respectively) was injected four times, dissolved in artificial cerebral spinal fluid (aCSF) at a final volume of $20 \mu \mathrm{l}$, at 24 and $12 \mathrm{~h}$ before ischemia induction, as well as immediately after ischemia onset and $6 \mathrm{~h}$ after. Vehicle-injected rats undergoing tMCAO or PC + tMCAO received i.c.v. aCSF in the same volume and on the same time schedule as TRAIL- or anti-TRAIL-treated animals. Animals were randomly allocated to each experimental group. The number of animals excluded because they died during the surgery procedures or because the reduction in the CBF was $<70 \%$ was the following: tMCAO vehicle-treated group: 2, 3; tMCAO $20 \mu \mathrm{g} / \mathrm{kg}$ anti-TRAIL: 1, 2; tMCAO $200 \mu \mathrm{g} / \mathrm{kg}$ anti-TRAIL: 0, 3; tMCAO $200 \mu \mathrm{g} / \mathrm{kg}$ scrambled anti-TRAIL: 1, 2; tMCAO $0.2 \mu \mathrm{g} / \mathrm{kg}$ TRAIL: 0, 3; tMCAO $6 \mu \mathrm{g} / \mathrm{kg}$ TRAIL: 1, 2; PC followed by tMCAO vehicle-treated group: 0,$1 ; P C$ followed by tMCAO $0.2 \mu \mathrm{g} / \mathrm{kg}$ TRAIL: 1, 3; and PC followed by tMCAO $6 \mu \mathrm{g} / \mathrm{kg}$ TRAIL: 2, 4 .

Evaluation of the infarct volume and of neurological deficit scores. Animals were killed by decapitation $24 \mathrm{~h}$ after $100 \mathrm{~min}$. Brains were quickly removed, sectioned coronally at $1-\mathrm{mm}$ intervals, and stained by immersion in the vital dye (2\%) 2,3,5-triphenyltetrazolium hydrochloride. The infarct volume was calculated by summing the infarction areas of all sections and by multiplying the total by slice thickness. To avoid that edema could affect the infarct volume value, it has been chosen to express the infarct volume as a percentage of the infarct, calculated by dividing the infarct volume by the total ipsilateral hemispheric volume. ${ }^{40,41}$

Neurological scores were evaluated $24 \mathrm{~h}$ after reperfusion according to two scales: a general neurological scale and a focal neurological scale. In the general score, the following six general deficits were measured: (1) hair conditions, (2) position of ears, (3) eye conditions, (4) posture, (5) spontaneous activity, and (6) epileptic behavior. For each of the six general deficits measured, animals received a score ranging between 0 and 12 depending on the severity of signs. The scores of investigated items were then summed to provide a total general score. In the focal score, the following seven areas were assessed: (1) body symmetry, (2) gait, (3) climbing, (4) circling behavior, (5) front limb symmetry, (6) compulsory circling, and (7) whisker response. For each of these items, animals were rated between 0 and 4 depending on severity. The seven items were then summed to give a total focal score. Infarct volumes, neurological scores, and animal survival were evaluated in a blinded manner.

Western blotting analysis. In the western blotting experiments, lysates were obtained from rats subjected to $\mathrm{IMCAO}$, ischemic $\mathrm{PC}$, or ischemic $\mathrm{PC}$ followed by $100 \mathrm{~min}$ tMCAO $24 \mathrm{~h}$ of reperfusion ( $n=3$ per group; 2 were excluded because of death and 3 excluded because $\mathrm{CBF}$ did not reach a reduction of at least $70 \%$ ). The protein concentration of the supernatant was determined by the 
a

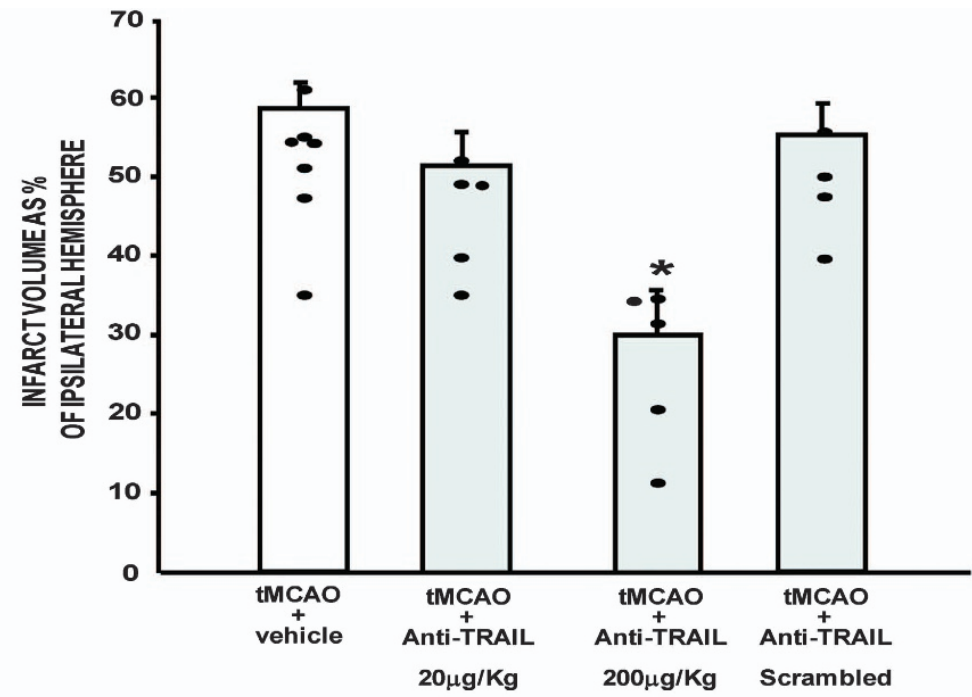

b

\section{General Deficits}
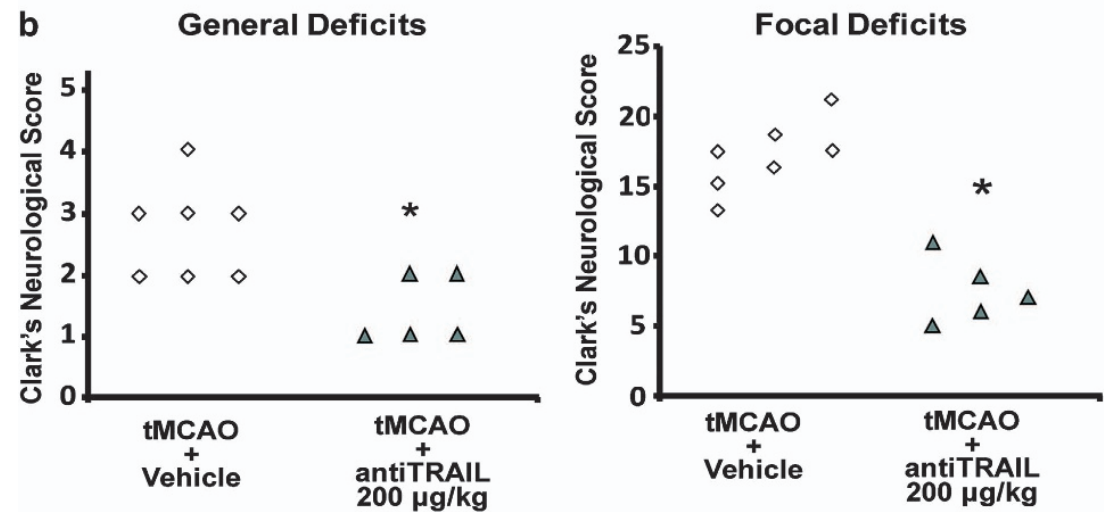

Figure 9 Effect of anti-TRAIL administration on ischemic damage elicited by $100 \mathrm{~min}$ of transient middle cerebral occlusion followed by 24 hours of reperfusion. (a) In all, $200 \mu \mathrm{g} / \mathrm{kg}$ antiTRAIL, i.c.v. injected, induces neuroprotection in rats subjected to tMCAO followed by $24 \mathrm{~h}$ reperfusion. Infarct volume in rats subjected to tMCAO + Vehicle, tMCAO $+20 \mu \mathrm{g} / \mathrm{kg}$ anti-TRAIL, tMCAO $+200 \mu \mathrm{g} / \mathrm{kg}$ anti-TRAIL, and tMCAO $+200 \mu \mathrm{g} / \mathrm{kg}$ scrambled anti-TRAlL. ${ }^{*} P<0.05$ versus all experimental groups. Each column represents the mean \pm S.E.M. $(n=5-7)$ of the percentage of the infarct volume compared with the ipsilateral hemisphere. (b) In all, $200 \mu \mathrm{g} / \mathrm{kg}$ antiTRAlL injected i.c.V. ameliorates general and focal deficits in rats subjected to $\mathrm{PC}+\mathrm{tMCAO}$. ${ }^{*} P<0.05$ versus vehicle-treated animals

Bradford method. ${ }^{42}$ Equal amounts of protein $(50 \mu \mathrm{g})$ were subjected to sodium dodecyl sulfate-polyacrylamide gel electrophoresis on 8 and $12 \%$ gels and then transferred onto Hybond ECL nitrocellulose membranes (Amersham Life Science, Buckinghamshire, UK). The membranes were blocked with 5\% milk in PBST and then incubated overnight at $4{ }^{\circ} \mathrm{C}$ with a rabbit anti-DR4 polyclonal antibody (ProSci Inc., Poway, CA, USA) or a rabbit anti-DR5 polyclonal antibody (Abcam, Cambridge, UK) or a rabbit anti-TRAIL polyclonal antibody (Abcam) or a rabbit anti-DcR1 (ProSci) polyclonal antibody or a rabbit anti-DcR2 polyclonal antibody (Abcam) or a rabbit anti-TNFRI polyclonal antibody (Abcam) or a rabbit anti-TNF alpha polyclonal antibody (Novus Biologicals, Littleton, CO, USA) or a mouse anti-Fas monoclonal antibody (BD Biosciences, San Jose, CA, USA) or a rabbit anti-FasL polyclonal antibody (Abcam) or a mouse anti-Caspase-8 monoclonal antibody (Cell Signaling Technology, Danvers, MA, USA) or a rabbit anti-Caspase-3 monoclonal antibody (Cell Signaling Technology) or a mouse anti-Phospho-JNK monoclonal antibody (Santa Cruz Biotechnology, Santa Cruz, CA, USA) or a rabbit anti-JNK polyclonal antibody (Santa Cruz Biotechnology) or a rabbit anti-PhosphoAkt monoclonal antibody (Cell Signaling Technology) or a rabbit anti-Akt monoclonal antibody (Cell Signaling Technology) and horseradish peroxidaseconjugated anti-rabbit or anti-mouse IgG secondary antibody (Amersham Life Science). $\beta$-Tubulin (Santa Cruz Biotechnology) was used as an internal control to validate the right amount of protein loaded in the gels. Detection was performed by means of ECL chemiluminescence assay (Amersham Life Science).

Immunohistochemistry. In immunofluorescence experiments, rats were subjected to $\mathrm{IMCAO}$, ischemic $\mathrm{PC}$, or ischemic PC followed by 100 min $\mathrm{tMCAO}$ at
5,24 , and $72 \mathrm{~h}$ of reperfusion ( $n=3$ per group; 1 excluded because of death and 2 excluded because CBF did not reach a reduction of at least $70 \%$ ). Immunostaining and confocal immunofluorescence procedures were performed as previously described. ${ }^{43}$ Rats were anesthetized with chloral hydrate $(300 \mathrm{mg} / \mathrm{kg}$, intraperitoneally) and perfused transcardially with $4 \%$ paraformaldehyde and $15 \%$ picric acid in phosphate buffer. The brains were sectioned coronally at $40 \mathrm{~mm}$ on a vibratome. After blocking, sections were incubated with the following primary antisera: mouse monoclonal anti-NeuN (1:1000, Millipore, Milan, Italy), rabbit polyclonal anti-TRAIL $(1: 200 ;$ Abcam), rabbit polyclonal anti-DcR2 (1:200; Abcam), rabbit polyclonal anti-DcR1 (1:200; ProSci), rabbit polyclonal anti-DR4 (1:200; ProSci), and rabbit polyclonal anti-DR5 (1:200; Abcam). The sections were incubated with the corresponding fluorescent-labeled secondary antibodies (Alexa 488/Alexa 594-conjugated antimouse/antirabbit IgGs). Images were observed using a Zeiss LSM510 META/laser scanning confocal microscope. Single images were taken with an optical thickness of $0.7 \mathrm{~m}$ and a resolution of $1024 \times 1024$.

In double-labeled sections, the pattern of immunoreactivity for both antigens was identical to that seen in single-stained material.

Controls of the methods in the double immunofluorescence experiments included replacement of the primary antisera with normal serum. To control for a possible cross-reactivity between $\mathrm{lgGs}$ in double immunolabeling experiments, some sections were processed through the same immunocytochemical sequence except that primary antisera were replaced with normal serum or only one primary antibody was applied, but the full complement of secondary antibodies was maintained. In addition, the secondary antibodies utilized were highly preadsorbed to the IgGs of 
numerous species. Tissue labeling without primary antibodies was also tested to exclude autofluorescence. No specific staining was observed under these control conditions, thus confirming the specificity of the immunosignals.

Statistical analysis. For the statistic ananlysis of the effect of TRAlL and anti-TRAIL on the infarct volume, data were expressed as mean \pm S.E., and statistical analysis was performed with two-way ANOVA followed by Newman-Keuls test.

The data related to focal and general neurological deficits, being non-parametric data, were analyzed using the non-parametric Kruskal-Wallis test, followed by the Nemenyi test for the non-parametric multiple comparison. Statistical significance was accepted at the $95 \%$ confidence level $(P<0.05)$.

\section{Conflict of Interest}

The authors declare no conflict of interest.

1. Lo EH, Dalkara T, Moskowitz MA. Mechanisms, challenges and opportunities in stroke. Nat Rev Neurosci 4: 399-415.

2. Donnan GA, Fisher M, Macleod M, Davis SM. Stroke. Lancet 2008; 371: 1612-1623.

3. Muir KW, Tyrrell P, Sattar N, Warburton E. Inflammation and ischaemic stroke. Curr Opin Neurol 2007; 20: 334-342.

4. Gidday JM. Cerebral preconditioning and ischaemic tolerance. Nat Rev Neurosci 2006; 7 : 437-448.

5. Nakajima T, Iwabuchi S, Miyazaki H, Okuma $\mathrm{Y}$, Kuwabara M, Nomura $\mathrm{Y}$ et al. Preconditioning prevents ischemia-induced neuronal death through persistent Akt activation in the penumbra region of the rat brain. J Vet Med Sci 2004; 66: 521-527.

6. Karikó K, Weissman D, Welsh FA. Inhibition of toll-like receptor and cytokine signaling-a unifying theme in ischemic tolerance. J Cereb Blood Flow Metab 2004; 24: 1288-1304.

7. Ceulemans A-G, Zgavc T, Kooijman R, Hachimi-Idrissi S, Sarre S, Michotte Y. The dual role of the neuroinflammatory response after ischemic stroke: modulatory effects of hypothermia. J Neuroinflammation 2010; 7: 74.

8. Barone FC, Feuerstein GZ. Inflammatory mediators and stroke: new opportunities for novel therapeutics. J Cereb Blood Flow Metab 1999; 19: 819-834.

9. Lucas S-M, Rothwell NJ, Gibson RM. The role of inflammation in CNS injury and disease. Br J Pharmacol 2006; 147(Suppl 1): S232-S240.

10. Cantarella G, Risuglia N, Lombardo G, Lempereur L, Nicoletti F, Memo M et al. Protective effects of estradiol on TRAIL-induced apoptosis in a human oligodendrocytic cell line: evidence for multiple sites of interactions. Cell Death Differ 2004; 11: 503-511.

11. Cantarella G, Lempereur L, D'Alcamo MA, Risuglia N, Cardile V, Pennisi G et al. Trail interacts redundantly with nitric oxide in rat astrocytes: potential contribution to neurodegenerative processes. J Neuroimmunol 2007; 182: 41-47.

12. Cantarella G, Uberti D, Carsana T, Lombardo G, Bernardini R, Memo M. Neutralization of TRAIL death pathway protects human neuronal cell line from beta-amyloid toxicity. Cell Death Differ 2003; 10: 134-141.

13. Wang J, Shen J, Gao Q, Ye Z, Yang S, Liang $H$ et al. Ischemic postconditioning protects against global cerebral ischemia/reperfusion-induced injury in rats. Stroke $J$ Cereb Circ 2008; 39: 983-990

14. Sheikh MS, Fornace AJ Jr. Death and decoy receptors and p53-mediated apoptosis. Leukemia 2000; 14: 1509-1513.

15. Pan G, Ni J, Wei YF, Yu G, Gentz R, Dixit VM. An antagonist decoy receptor and a death domain-containing receptor for TRAlL. Science 1997; 277: 815-818.

16. Walczak H, Degli-Esposti MA, Johnson RS, Smolak PJ, Waugh JY, Boiani N et al. TRAIL-R2: a novel apoptosis-mediating receptor for TRAIL. EMBO J 1997; 16: 5386-5397.

17. Cui M, Wang L, Liang X, Ma X, Liu Y, Yang M et al. Blocking TRAlL-DR5 signaling with soluble DR5 reduces delayed neuronal damage after transient global cerebral ischemia. Neurobiol Dis 2010; 39: 138-147.

18. Huang Z, Song L, Wang C, Liu J-Q, Chen C. Hypoxia-ischemia upregulates TRAIL and TRAIL receptors in the immature rat brain. Dev Neurosci 2011; 33: 519-530.

19. Panneerselvam M, Patel PM, Roth DM, Kidd MW, Chin-Lee B, Head BP et al. Role of decoy molecules in neuronal ischemic preconditioning. Life Sci 2011; 88: 670-674.

20. Cantarella G, Di Benedetto G, Scollo M, Paterniti I, Cuzzocrea S, Bosco P et al. Neutralization of tumor necrosis factor-related apoptosis-inducing ligand reduces spinal cord injury damage in mice. Neuropsychopharmacology 2010; 35: 1302-1314.

21. Park S-Y, Billiar TR, Seol D-W. Hypoxia inhibition of apoptosis induced by tumor necrosis factor-related apoptosis-inducing ligand (TRAIL). Biochem Biophys Res Commun 2002; 291: 150-153.

22. Cantarella G, Di Benedetto G, Pezzino S, Risuglia N, Bernardini R. TRAlL-related neurotoxicity implies interaction with the Wnt pathway in human neuronal cells in vitro. J Neurochem 2008; 105: 1915-1923.
23. Cantarella G, Di Benedetto G, Martinez G, Loreto C, Clementi G, Cantarella A et al. Amylin prevents TRAIL-mediated apoptotic effects of reserpine in the rat gastric mucosa. Peptides 2009; 30: 1466-1472.

24. Sancilio S, Di Giacomo V, Quaglietta AM, lacone A, Angelucci D, Tatasciore U et al. TRAIL promotes a pro-survival signal in erythropoietin-deprived human erythroblasts through the activation of an NF-kB/kBalpha pathway. J Biol Regul Homeost Agents 2011; 25: 375-386.

25. LeBlanc HN, Ashkenazi A. Apo2L/TRAIL and its death and decoy receptors. Cell Death Differ 2003; 10: 66-75.

26. Crowder RN, El-Deiry WS. Caspase-8 regulation of TRAIL-mediated cell death. Exp Oncol 2012; 34: 160-164.

27. Fu L, Lin Y-D, Elrod HA, Yue P, Oh Y, Li B et al. c-Jun NH2-terminal kinase-dependent upregulation of DR5 mediates cooperative induction of apoptosis by perifosine and TRAIL. Mol Cancer 2010; 9: 315.

28. Martin-Villalba A, Herr I, Jeremias I, Hahne M, Brandt R, Vogel J et al. CD95 ligand (Fas-L/APO-1 L) and tumor necrosis factor-related apoptosis-inducing ligand mediate ischemia-induced apoptosis in neurons. J Neurosci 1999; 19: 3809-3817.

29. Ozaki K, Leonard WJ. Cytokine and cytokine receptor pleiotropy and redundancy. J Biol Chem 2002; 277: 29355-29358.

30. Croft M, Benedict CA, Ware CF. Clinical targeting of the TNF and TNFR superfamilies. Nat Rev Drug Discov 2013; 12: 147-168.

31. Lanzillotta A, Pignataro G, Branca C, Cuomo O, Sarnico I, Benarese M et al. Targeted acetylation of NF-kappaB/RelA and histones by epigenetic drugs reduces post-ischemic brain injury in mice with an extended therapeutic window. Neurobiol Dis 2012; 49C: 177-189.

32. Valsecchi V, Pignataro G, Del Prete A, Sirabella R, Matrone C, Boscia F et al. NCX1 is a novel target gene for hypoxia-inducible factor-1 in ischemic brain preconditioning. Stroke $J$ Cereb Circ 2011; 42: 754-763.

33. Degli-Esposti MA, Dougall WC, Smolak PJ, Waugh JY, Smith CA, Goodwin RG. The novel receptor TRAIL-R4 induces NF-kappaB and protects against TRAIL-mediated apoptosis, yet retains an incomplete death domain. Immunity 1997; 7: 813-820.

34. Travert M, Ame-Thomas P, Pangault C, Morizot A, Micheau O, Semana G et al. CD40 ligand protects from TRAIL-induced apoptosis in follicular lymphomas through NF-kappaB activation and up-regulation of C-FLIP and Bcl-xL. J Immunol 2008; 181: 1001-1011.

35. Mendoza FJ, Ishdorj G, Hu X, Gibson SB. Death receptor-4 (DR4) expression is regulated by transcription factor NF-kappaB in response to etoposide treatment. Apoptosis 2008; 13: 756-770.

36. Chen J-J, Chou C-W, Chang Y-F, Chen C-C. Proteasome inhibitors enhance TRAILinduced apoptosis through the intronic regulation of DR5: involvement of NF-kappa B and reactive oxygen species-mediated p53 activation. J Immunol 2008; 180: 8030-8039.

37. Pei G-T, Wu C-W, Lin W-W. Hypoxia-induced decoy receptor 2 gene expression is regulated via a hypoxia-inducible factor 1alpha-mediated mechanism. Biochem Biophys Res Commun 2010; 391: 1274-1279.

38. Pignataro G, Meller R, Inoue K, Ordonez AN, Ashley MD, Xiong Z et al. In vivo and in vitro characterization of a novel neuroprotective strategy for stroke: ischemic postconditioning. $J$ Cereb Blood Flow Metab 2008; 28: 232-241.

39. Paxinos G, Watson C. The Rat Brain in Stereotaxic Coordinates: Hard Cover Edition. Academic Press: New York, 2007.

40. Pignataro G, Gala R, Cuomo O, Tortiglione A, Giaccio L, Castaldo P et al. Two sodium/calcium exchanger gene products, NCX1 and NCX3, play a major role in the development of permanent focal cerebral ischemia. Stroke 2004; 35: 2566-2570.

41. Pignataro G, Boscia F, Esposito E, Sirabella R, Cuomo O, Vinciguerra A et al. NCX1 and NCX3: two new effectors of delayed preconditioning in brain ischemia. Neurobiol Dis 2012; 45: 616-623.

42. Bradford MM. A rapid and sensitive method for the quantitation of microgram quantities of protein utilizing the principle of protein-dye binding. Anal Biochem 1976; 72: 248-254.

43. Pignataro G, Esposito E, Cuomo O, Sirabella R, Boscia F, Guida N et al. The NCX3 isoform of the $\mathrm{Na}+/ \mathrm{Ca} 2+$ exchanger contributes to neuroprotection elicited by ischemic postconditioning. J Cereb Blood Flow Metab 2011; 31: 362-370.

(c) (i) (2) $\odot$ Cell Death and Disease is an open-access journal published by Nature Publishing Group. This work is licensed under a Creative Commons Attribution-NonCommercialNoDerivs 3.0 Unported License. The images or other third party material in this article are included in the article's Creative Commons license, unless indicated otherwise in the credit line; if the material is not included under the Creative Commons license, users will need to obtain permission from the license holder to reproduce the material. To view a copy of this license, visit http://creativecommons.org/licenses/ by-nc-nd/3.0/ 